\title{
Studies in Bioactive Marine Alkaloids
}

\author{
Makoto Kuramoto, Hirokazu Arimoto ${ }^{\dagger}$, and Daisuke Uemura ${ }^{\dagger *}$ \\ Department of Material Science, Integrated Center for Science, Ebime University, \\ ${ }^{\dagger}$ Department of Chemistry, Graduate School of Science, Nagoya University,
}

Received June 27, 2003

\begin{abstract}
In our continuing search for bioactive substances from marine organisms, novel alkaloids were isolated. The structures and functions of these marine alkaloids are described here.

Pinnatoxins and pteriatoxins, potent shellfish poisons, were purified from the Okinawan bivalve Pinna muricata. Pinnatoxins activate $\mathrm{Ca}^{2+}$ channels. Halichlorine was isolated from the marine sponge Halichondria okadai. This compound inhibits the induction of VCAM-1. Drugs that block VCAM-1 may be useful for treating coronary artery diseases, angina, and noncardiovascular inflammatory diseases. Pinnaic acids, which are $\mathrm{cPLA}_{2}$ inhibitors, were also obtained from $P$. muricata. Interestingly, the structures of pinnaic acids are closely related to that of halichlorine. Norzoanthamine hydrochloride, isolated from the colonial zoanthid Zoanthus sp., suppresses decreases in bone weight and strength in ovariectomized mice, and could be a good candidate for an osteoporotic drug. Aburatubolactams, inhibitors of superoxide anion generation, were isolated from Streptomyces sp.
\end{abstract}

\section{Introduction}

Alkaloids have been defined as nitrogen-containing, basic compounds isolated from plants. Although it is not clear why alkaloids show significant biological activity, they are often useful as drugs or biological probes for physiological studies. As new and more complicated, unexpected diseases appear worldwide, the importance of bioactive alkaloids has increased due to their potential application as chemotherapy. As the application of alkaloids has expanded, the definition of alkaloids has become less restricted. Alkaloids are now widely accepted as nitrogen-containing compounds that occur naturally not only in plants but also in microorganisms, marine organisms, and animals.

\section{Pinnatoxins: $\mathrm{Ca}^{2+}$ Channel-Activating Shellfish Poisons}

Shellfish of the genus Pinna live mainly in shallow waters of the temperate and tropical zones of the Indian and Pacific Oceans. ${ }^{1}$ The adductor muscle of this bivalve is eaten in Japan and China, and food poisoning resulting from its ingestion occurs frequently. ${ }^{2}$ Chinese investigators have reported that a toxic extract from $P$. attenuata, referred to as pinnatoxin, is a $\mathrm{Ca}^{2+}$ channel activator. ${ }^{3}$ We isolated the following novel toxins from $P$. muricata: pinnatoxins $\mathrm{A}(\mathbf{1}), \mathrm{B}(\mathbf{2})$,
$\mathrm{C}(3)$, and $\mathrm{D}(4){ }^{4}$ (Fig. 1)

\subsection{Isolation and Structure of Pinnatoxins}

The viscera $(45 \mathrm{~kg})$ of $P$. muricata collected in Okinawa, Japan, were extracted with $75 \%$ ethanol. The extract was filtered and the concentrated filtrate was washed with ethyl acetate and evaporated. The oily residue was successively chromatographed on TSK G-3000S polystyrene gel, Sephadex LH-20, DEAE Sephadex A-25, and ODS-AQ, using a bioassay-guided (intraperitoneal mouse lethality) fractionation. Final purification was achieved by reverse-phase HPLC to give pinnatoxin A $(3.5 \mathrm{mg})$, a mixture of $\mathrm{B}$ and $\mathrm{C}(1.2 \mathrm{mg})$, and $\mathrm{D}(2.0 \mathrm{mg})$.

The structures of pinnatoxins $\mathrm{A}$ and $\mathrm{D}$ were clarified by 2D NMR experiments. Although pinnatoxins $\mathrm{B}$ and $\mathrm{C}$ were obtained as a detachable mixture, the gross structures were determined by the analysis of $2 \mathrm{D}$ NMR and positive ion ESI MS/MS spectra. ${ }^{5}$ The relative stereochemistry of pinnatoxins was established by NOE experiments.

Pinnatoxins consist of a 20 -membered ring, i.e., the 5,6-bicyclo, 6,7-azaspiro, and 6,5,6-triketal moiety in their structure. In particular, pinnaic acids comprise a carboxylate anion and an iminium cation or an ammonium cation.

\subsection{Biological Activity of Pinnatoxins}

Pinnatoxin $\mathrm{A}(\mathbf{1})$ showed potent acute toxicity against mice

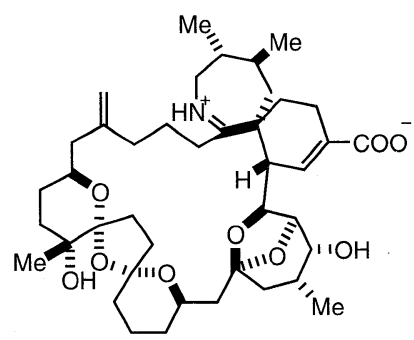

Pinnatoxin A (1)

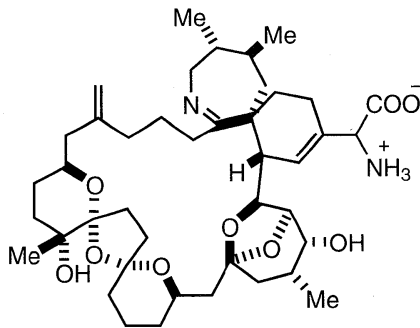

Pinnatoxin B (2): $34 S$ isomer Pinnatoxin C (3): $34 R$ isomer

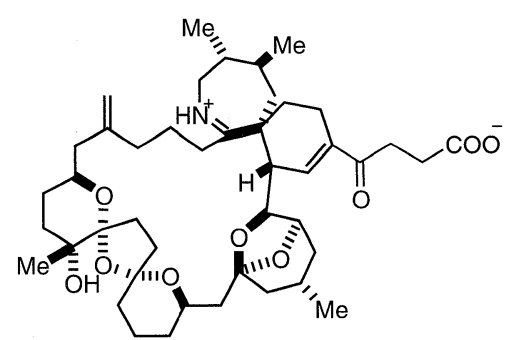

Pinnatoxin D (4)

Figure 1. Structures of pinnatoxins. 
( $\mathrm{LD}_{50} 2.7 \mu \mathrm{g} / \mathrm{MU}$ (i.p.)). It was noted that the toxicity of $\mathbf{2}, \mathbf{3}$ $\left(\mathrm{LD}_{50} 0.99 \mu \mathrm{g} / \mathrm{MU}\right)$ was as potent as that of tetrodotoxin. Although the acute toxicity of $4\left(\mathrm{LD}_{50}>10 \mu \mathrm{g} / \mathrm{MU}\right)$ was weaker than that of the other pinnatoxins, 4 showed the strongest cytotoxicity against a murine leukemia cell line P388 ( $\left.\mathrm{IC}_{50} 2.5 \mu \mathrm{g} / \mathrm{ml}\right)$.

Extracts from the digestive glands of several Pinna sp., including $P$. muricata, $P$. attenuata, $P$. atropupurea, and the commonly eaten shellfish Atrina pectinata, all produced the same symptoms of poisoning in mice. These data suggest that Pinna shellfish may become toxic as the result of feeding on toxic organisms such as dinoflagellates. ${ }^{6}$

\subsection{Biogenesis of the Pinnatoxin Family}

Pteriatoxins $\mathrm{A}(\mathbf{5}), \mathrm{B}$, and $\mathrm{C}(\mathbf{6}, 7$ : a 1:1 mixture) were also isolated from the Okinawan bivalve Petria penguin. ${ }^{6}$ Pteriatoxins $(\mathbf{5}, \mathbf{6}$, and $\mathbf{7})$ showed significant acute toxicity against mice $\left(\mathrm{LD}_{99} 100 ; 8 \mathrm{mg} / \mathrm{kg}\right)$. Based on an analysis of positive ESI MS/MS spectra, ${ }^{5}$ pteriatoxins were determined to be pinnatoxin analogs containing a cysteine moiety. (Fig. 2)

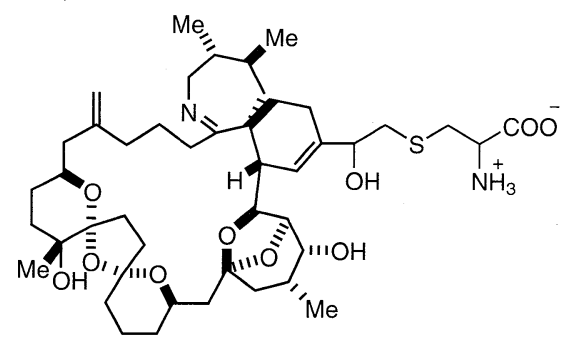

Pteriatoxin A (5)

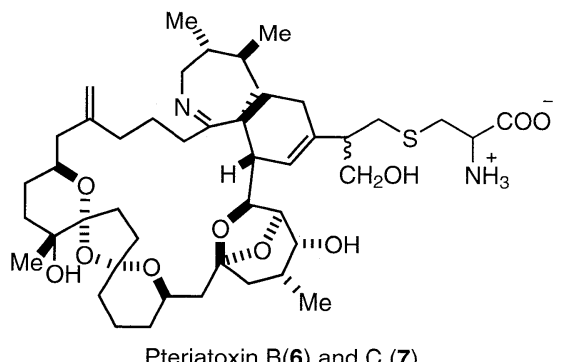

Pteriatoxin $\mathrm{B}(\mathbf{6})$ and $\mathrm{C}(\mathbf{7})$

Figure 2. Structures of pteriatoxins.

Interestingly, the backbone of pinnatoxins and their analogues could be configured from $\mathrm{C} 1$ to $\mathrm{C} 34$ in a single carbon chain. Marine organisms usually produce super carbon chain molecules with a terminal amino group, e.g., palytoxin. In this study, we have proposed a polyketide biogenetic pathway for pinnatoxins, shown in Fig. 3.

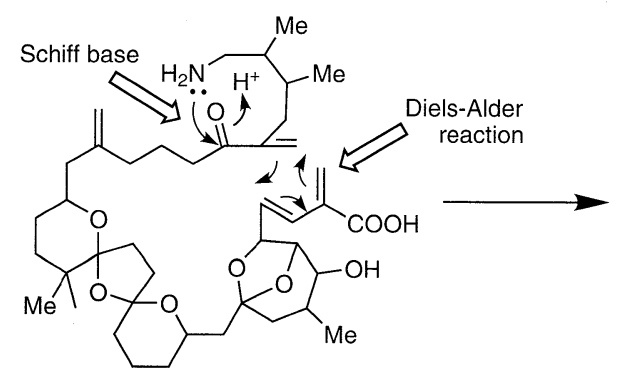

\section{Halichlorine: an Inhibitor of VCAM-1 Induction}

Adhesion molecules are involved in the processes of adhesion between cells and adhesion between cells and the extracellular matrix in the formation of multicellular bodies. In addition, it is known that the activity of adhesive molecules is very important for the maintenance of function and performance. A recent study indicated that the clinical application of adhesion molecules as anti-inflammatory agents and immunosuppressive agents may some day be possible, provided that the function of the adhesive molecules is controlled. ${ }^{7}$

A simple model of multistage adhesion between leukocyte and vascular cells is shown in Fig. 4. This process can be classified into four stages, i.e., 1) Rolling, 2) Triggering, 3) Strong Adhesion, and 4) Transmigration. VCAM-1 ${ }^{8}$ (vascular cell adhesion molecule-1) is affected during the phase of Strong Adhesion. Drugs that block the induced expression of VCAM-1 may be useful for treating atherosclerosis, coronary artery diseases, angina, and noncardiovascular inflammatory diseases. $^{7}$

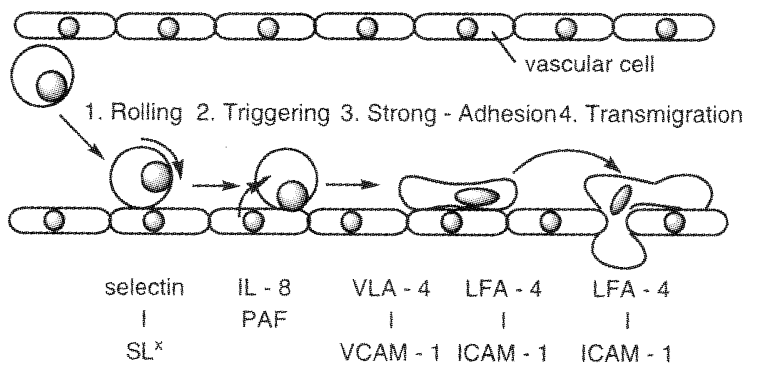

Figure 4. A model of adhesion between leukocyte and vascular cells.

\subsection{Isolation and Structure of Halichlorine}

The marine sponge $H$. okadai Kadota $(200 \mathrm{~kg})$ was immersed in ethanol at room temperature. The ethanolic extract was filtered, concentrated under reduced pressure, and extracted with ethyl acetate. The ethyl acetate extract was partitioned between $70 \%$ aqueous methanol and hexane. The aqucous methanol layer was separated by column chromatography on TSK G3000S, then on ODS, and then on $\mathrm{SiO}_{2}$. Finally, the active fraction was purified by preparative TLC on $\mathrm{SiO}_{2}$ to give crystalline halichlorine (7) $(70.8 \mathrm{mg}){ }^{9}$

The structure of 7 was elucidated by an analysis of the MS and the extensive 2D NMR spectra, as shown in Fig. 5. Halichlorine consists of a sterically hindered 15-membered lactone, an azabicyclo [4.4.0] ring, and a [5.6]-spiro ring moiety. The relative stereochemistry of 7 was clarified mainly by the coupling constants and NOESY spectral data. Furthermore, the Bohlmann band ${ }^{10}$ in the IR spectrum suggested the

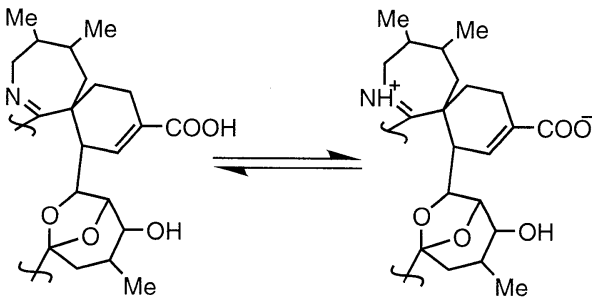

Figure 3. Proposed biogenesis of pinnatoxin A. 


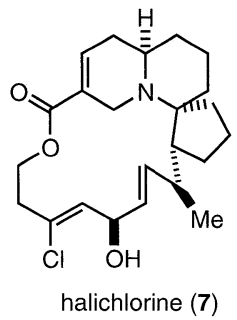

Figure 5. Structure of halichlorine.

conformation around the tertiary amine functionality.

The absolute stereochemistry of 7 was clarified by compositional techniques. Oxidative degradation of 7 , as well as the asymmetric synthesis of the degradation product, allowed us to determine the absolute stereochemistry of halichlorine. ${ }^{11}$ The first total synthesis by Danishefsky et al. ${ }^{12}$ also supported our conclusions for the structure of 7 .

\subsection{Biological Activity of Halichlorine}

Halichlorine inhibits the induction of VCAM-1 at $\mathrm{IC}_{50} 7$ $\mu \mathrm{g} / \mathrm{ml}$. Although VCAM-1 and ICAM belong to the same immunoglobulin superfamily, halichlorine does not affect ICAM $\left(\mathrm{IC}_{50}>100 \mu \mathrm{g} / \mathrm{ml}\right) .^{6,13}$ It remains largely unknown why halichlorine affects only VCAM-1. Thus, additional research will be needed to clarify the functions and mechanisms of action of VCAM-1.

\section{Pinnaic acids: cPLA 2 Inhibitors}

Specific inhibitors of phospholipase $\mathrm{A}_{2}\left(\mathrm{PLA}_{2}\right)$ have been considered as potential drugs for the treatment of inflammation and other disease states, since PLA $\mathrm{PL}_{2}$ is linked to the initial step in the cascade of enzymatic reactions which lead to the generation of inflammatory mediators. ${ }^{14}$ Marine natural products such as manoalide ${ }^{15}$ and luffariellolide ${ }^{16}$ have been reported to be potent PLA 2 inhibitors. ${ }^{17}$ A cytosolic $85-\mathrm{kDa}$ phospholipase $\left(\mathrm{cPLA}_{2}\right)^{18}$ exhibits specificity for the release of arachidonic acid from membrane phospholipids. ${ }^{19}$ Therefore, compounds that inhibit cPLA ${ }_{2}$ activity have been targeted as anti-inflammatory agents.

\subsection{Isolation and Structure of Pinnaic Acids}

The $80 \%$ EtOH extract of the viscera $(10 \mathrm{~kg})$ of $P$. muricata (3,000 individuals) was partitioned between EtOAc and water. The water layer was fractionated by column chromatography on TSK G-3000S polystyrene gel, Sephadex LH-20, DEAE Sephadex A-25, ODS-AQ, and silica gel to obtain two novel fatty acids, i.e., pinnaic acid (8) $(1 \mathrm{mg})$ and tauropinnaic acid (9) $(4 \mathrm{mg}){ }^{20}$ (Fig. 6)

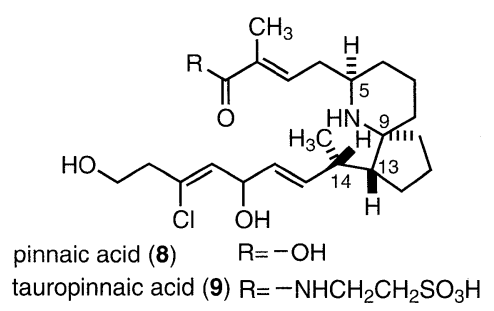

Figure 6. Structures of pinnaic acids.

The structure of 9 was determined by the analysis of NMR spectral data. Tauropinnaic acid (9) has a 6-azaspiro[4.5] decane unit and a taurine moiety. The relative stereochem- istry of 9 was deduced from phase-sensitive NOE correlations. Furthermore, the gross structure of $\mathbf{8}$ was elucidated by a detailed comparison of the EI-MS fragment peaks with the corresponding peaks of 9 . Interestingly, the structure of pinnaic acid has been shown to be quite similar to that of halichlorine (7). Although the absolute stereochemistry of 7 has been fully established, the scarcity of $\mathbf{8}$ among natural sources has allowed only the assignment of the relative stereochemical relationships between $\mathrm{C} 5, \mathrm{C} 9$, and $\mathrm{C} 13$. We tentatively reported the $\mathrm{C} 14$ configuration as epimeric to the structure of $\mathbf{8}^{20}$ However, from a biogenetic point of view, this conclusion is open to question, in particular when the configuration at $\mathrm{C} 14$ is compared to that of halichlorine. Synthetic studies of pinnaic acid (vide infra) unambiguously establish that the relative stereochemistry of pinnaic acid is similar to that of $7 .^{21,22}$

\subsection{Biological Activities of Pinnaic Acids}

Pinnaic acid (8) and tauropinnaic acid (9) inhibited CPLA $_{2}$ activity in vitro with $\mathrm{IC}_{50}$ values of $0.2 \mathrm{mM}$ and $0.09 \mathrm{mM}$, respectively. Although the activity of pinnaic acids was moderate, inhibitors of $\mathrm{CPLA}_{2}$ have not yet been reported to date. Therefore, it is necessary to clarify the mechanism of action of these inhibitors.

\subsection{Biogenesis of Pinnaic Acids}

As described above, pinnaic acids are closely related to halichlorine. Therefore, each carbon atom has been tentatively numbered according to biogenetic consideration of the formation of the $\mathrm{N}-\mathrm{C} 23$ bond. (Fig. 7) It is possible that these bioactive compounds from marine organisms are produced by symbiotic microorganisms. Further studies of the detailed chemistry of pinnaic acids, including biogenetic pathways and structure-activity relationships, are currently underway in our laboratory.

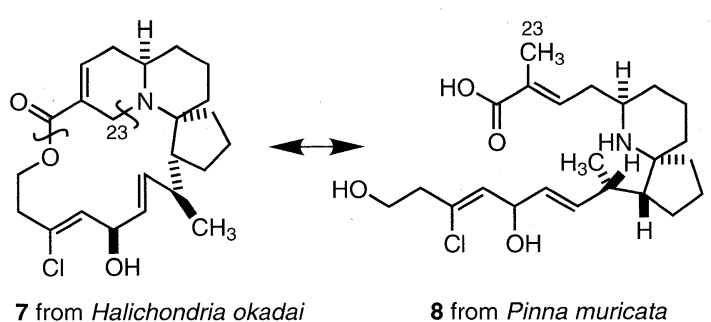

Figure 7. Biogenesis of pinnaic acids and halichlorine.

\subsection{Total Synthesis of Pinnaic Aid}

These architecturally novel alkaloids have attracted the attention of synthetic chemists; to date, 14 research groups have published synthetic studies of these alkaloids. The Danishefsky group has achieved the total synthesis of halichlorine $\mathrm{e}^{20}$ and pinnaic acid ${ }^{21}$ in an asymmetric manner.

In their synthetic process, it was assumed that pinnaic acid had the same absolute configuration around the aza-spirocyclic moiety (C5, C9, C13), and that all four possible diastereomers at $\mathrm{C} 14$ and $\mathrm{C} 17$ were synthesized. Comparison of the NMR spectra of these synthetic samples with the data reported for the natural products made it possible to revise the relative structure for pinnaic acid as $\mathbf{8}$.

As pinnaic acid is a zwitterionic molecule, the NMR spectrum is quite sensitive to the measurement conditions. We recently reported a racemic total synthesis of $\mathbf{8}$ (Scheme 1), ${ }^{22}$ 
Scheme 1. Synthesis of $( \pm)$-pinnaic acid 22

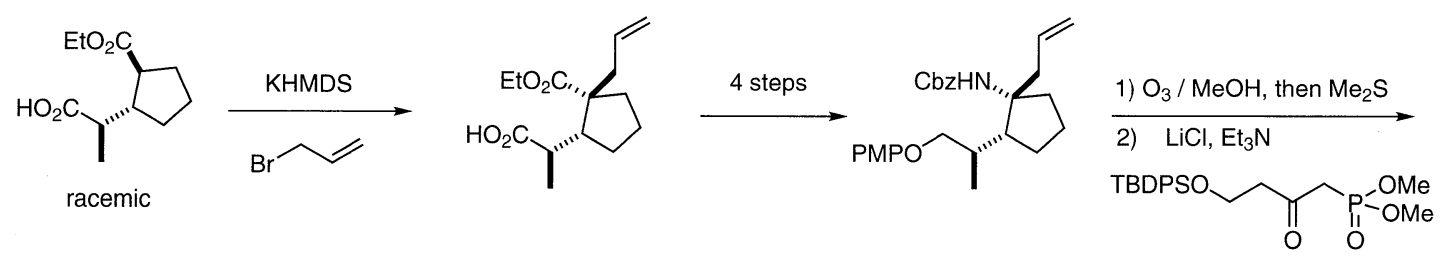

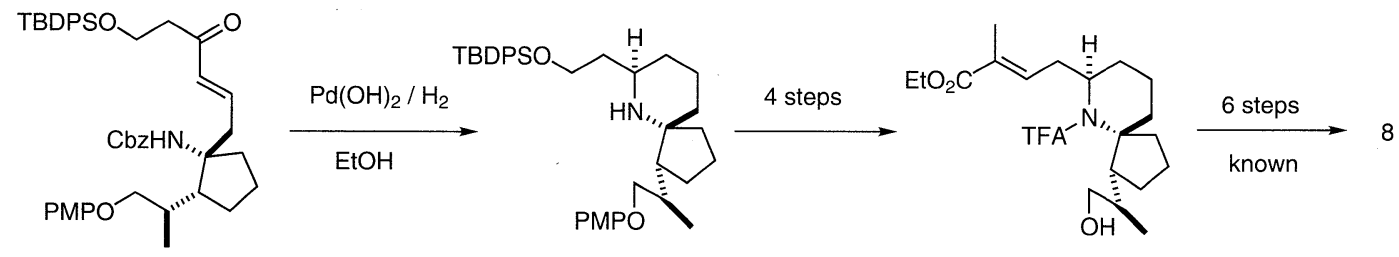

and our detailed comparison of the ${ }^{1} \mathrm{H}-\mathrm{NMR}$ spectra of both synthetic and natural samples supported Danishefsky's revision of the configuration at $\mathrm{C} 14$.

\section{Norzoanthamine: a Significant Inhibitor of Osteoporosis}

Osteoporosis is caused by an imbalance between bone resorption and bone formation, which results in bone loss and fractures after mineral flux occurs. The frequency of fracture is significantly increased in patients with osteoporosis, and hip fracture in elderly patients with osteoporosis is a very serious problem because it often limits their quality of life. Therefore, in addition to preventing the loss of bone mass, the maintenance of the mechanical strength of bone tissue is a very important point to consider in the development of novel anti-osteoporotic drugs. ${ }^{23}$

Norzoanthamine $(\mathbf{1 0})^{24}$ and its homologues $(\mathbf{1 1 - 1 8})^{24,25}$ were isolated from the genus Zoanthus sp. (Fig. 8) Norzoanthamine inhibits IL-6 production. ${ }^{26}$ Furthermore, norzoanthamine and norzoanthamine hydrochloride, both of which counteract decreases in bone weight and strength in ovariectomized mice, could be a good candidate for osteoporotic drug. ${ }^{23,27}$ The relative stereochemistry of norzoanthamines was determined hy $\mathrm{X}$-ray analysis ${ }^{24}$ Furthermore, the ahsolute stereochemistry of norzoanthamine was determined by an advanced version of Mosher's method, as shown in Fig. $8 .^{26 \mathrm{a}}$

\subsection{Biological Activity of Norzoanthamine}

The effect of norzoanthamine hydrochloride on bone weight and strength was tested in ovariectomized mice, a postmenopausal osteoporosis model. ${ }^{26,28}$ Norzoanthamine hydrochloride $(0.08 \mathrm{mg} / \mathrm{kg} /$ day, p.o.) significantly suppressed the decrease in femoral weight caused by ovariectomy without an increase in uterine weight. (Fig. 9) Such data suggested that the mode of action of norzoanthamine hydrochloride differs from that of estrogen. ${ }^{29}$ Furthermore, failure load and yield energy of the femur were maintained by the administration of norzoanthamine hydrochloride at a dose of 0.4 $\mathrm{mg} / \mathrm{kg} /$ day (p.o.), respectively. (Fig. 10) Finally, the thickness of the cortical bone was measured by a photograph of the ground bone. Ovariectomy caused a decrease in the humeralis trabeculae. (Fig. 11) Norzoanthamine hydrochloride significantly suppressed this decrease in a dose-dependent manner. (Fig. 11C, D, E) In ovariectomized mice treated with norzoanthamine hydrochloride, the primary spongiosa had not significantly increased, and the morphology of the metaphysis remained nearly normal.

II -6 is known as a stimulator of osteoclast formation, and suppression of IL-6 secretion can be effective in the preven-
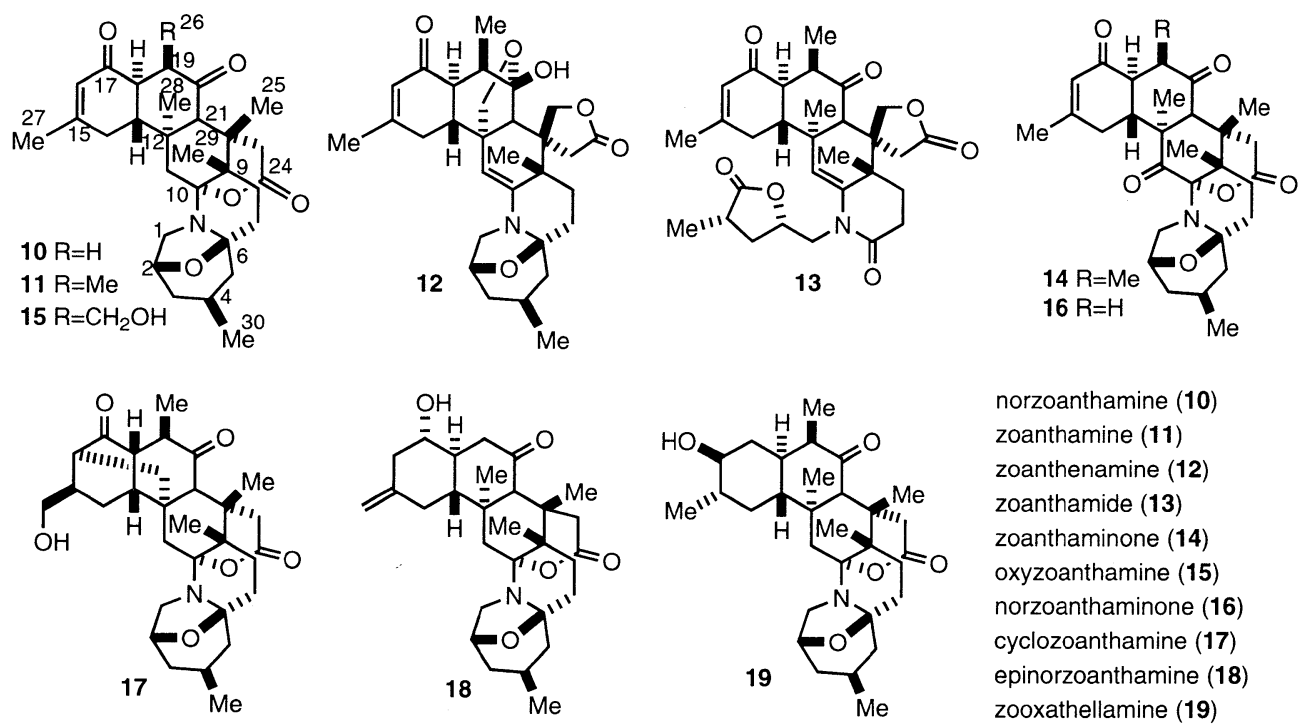

norzoanthamine (10) zoanthamine (11) zoanthenamine (12) zoanthamide (13) zoanthaminone (14) oxyzoanthamine (15) norzoanthaminone (16) cyclozoanthamine (17) epinorzoanthamine (18) zooxathellamine (19)

Figure 8. Structures of zoanthamine-type alkaloids. 

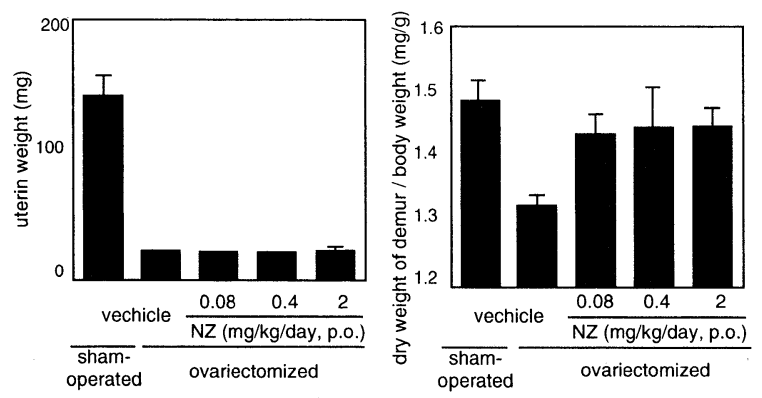

Figure 9. Effects of norzoanthamine hydrochloride on uterine and femoral weight.
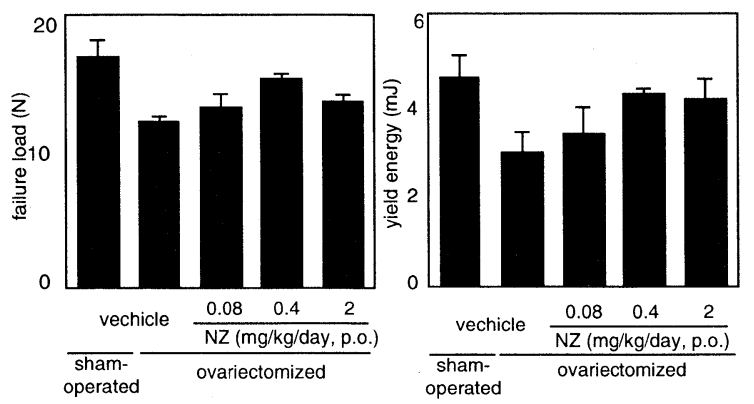

Figure 10. Effects of norzoanthamine hydrochloride on failure load and yield energy.

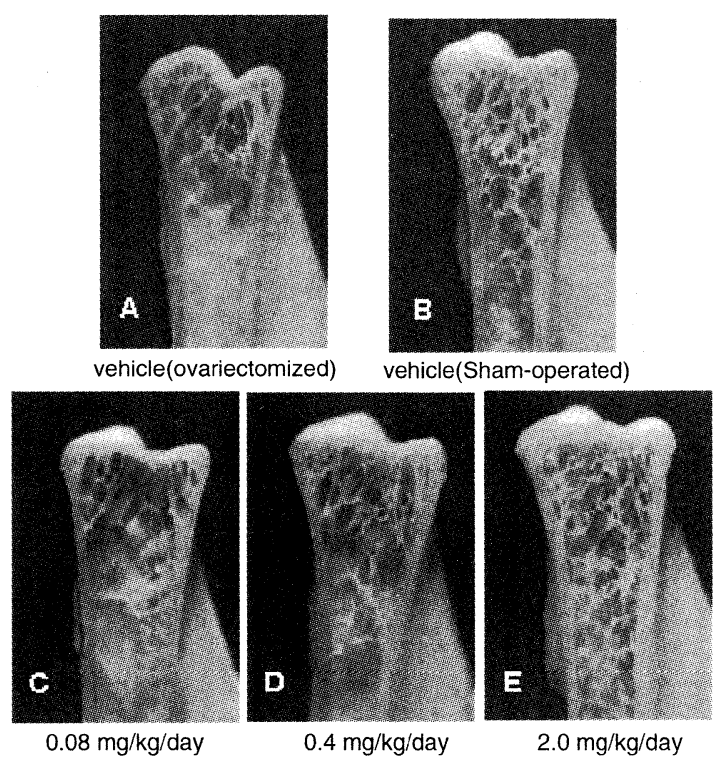

norzaonthamine hydrochloride (ovariectomized)

Figure 11. Effect of norzoanthamine hydrochloride on humeralis morphology in ovariectomized mice.

tion of osteoporosis. Norzoanthamine and norzoanthamine hydrochloride inhibit IL-6 induction at values of 13 and 4.7 $\mu \mathrm{g} / \mathrm{ml}$, respectively.

\subsection{Biogenesis of Zoanthamines}

Based on their molecular formulas, zoanthamines have been regarded as terpenoids; however, the biogenetic pathway of zoanthamines remains unclear. As described above, marine organisms usually produce super carbon chain molecules with a terminal amino group. Here, we propose a polyketide biogenetic pathway for zoanthamines, shown in Fig. 12.

Interestingly, Nakamura's group isolated zooxathellamine
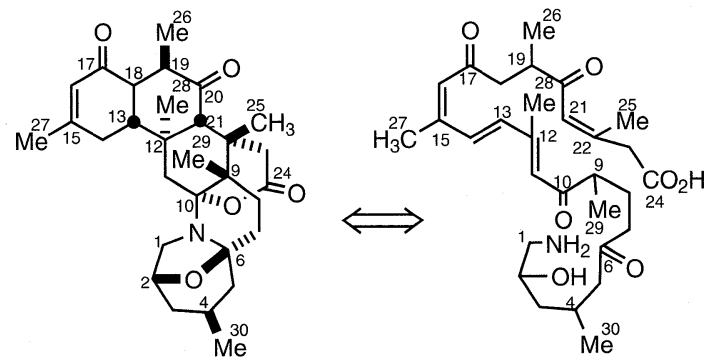

Figure 12. Proposed biogenesis of zoanthamines.

(19, Fig. 8) from a symbiotic dinoflagellate Symbiodinium sp. $^{30}$ The absolute stereochemistry of $\mathbf{1 9}$ was the same as that of norzoanthamine. The structural similarity of $\mathbf{1 9}$ to that of the zoanthid alkaloids suggests an algal origin for these zoanthamines. Furthermore, a feeding experiment with a labeled compound suggested the biosynthetic pathway of 19 . This pathway was similar to that suggested in our previous proposal.

\section{Aburatubolactams: Inhibitors of Superoxide Anion Gen- eration from Marine Microorganisms}

As described above, extremely bioactive, structurally novel compounds have been found in marine organisms. However, their practical use in drugs is considerably limited because of the extraordinarily low amount of physiologically active compounds obtainable from these marine organisms. Therefore, research has necessarily focused on the metabolites of such marine organisms, which most likely are the true producers of the active compounds. Aburatubolactams were isolated from the cultured broth of a Streptomyces sp., SCRC-A20, in a study monitoring the inhibition of superoxide anion generation. $^{31}$

\subsection{Isolation and Structure of Aburatubolactams}

The cultured broth $(100 \mathrm{~L})$ of SCRC-A20 was separated into supernatants and mycelium by filtration. The supernatant was AcOEt, and the mycelium was then extracted with $\mathrm{MeOH}$. The combined extract was fractionated by a column chromatography on $\mathrm{SiO}_{2}, \mathrm{LH}-20$, and ODS, while bioactivity was monitored. Finally, aburatubolactam A (20, 1 $\mathrm{mg}), \mathrm{B}(\mathbf{2 1}, 16 \mathrm{mg})$, and C $(\mathbf{2 2}, 140 \mathrm{mg})$ were purified by preparative TLC. ${ }^{32}$
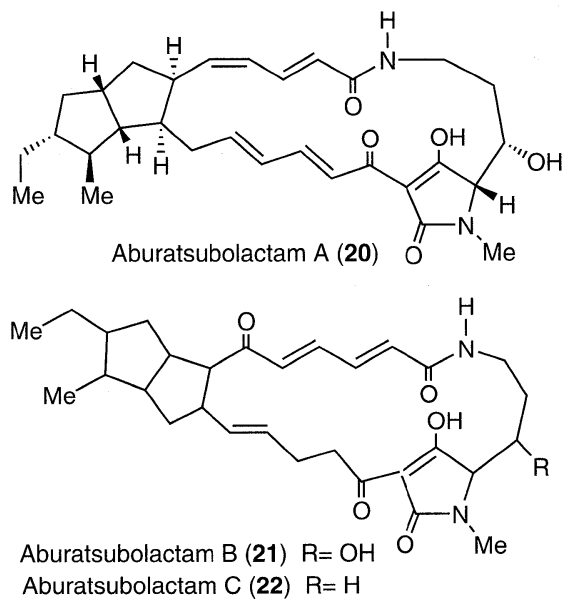

Figure 13. Structures of aburatubolactams. 
The structures of these compounds were mainly determined by NMR analysis. Fortunately, a single crystal of aburatubolactam $\mathrm{A}$ was obtained from $\mathrm{MeOH}$. The structure of the 20-membered macrocyclic structure is thought to be with the diene amide and dienone functionalities. The coplanar structure of the diene amide and the triketone moiety is very remarkable in this molecule. The structures of other aburatubolactams were deduced by detailed comparison of the NMR spectra with that of aburatubolactam A. (Fig. 13)

Aburatubolactams, which possess an acyl tetramine structure, are biogenetically related to the following: ikarugamycin $^{33}$ from a terrestrial actinomycete, alteramide $\mathrm{A}^{34}$ from a marine bacterium, and cyrindramine ${ }^{35}$ from a marine sponge. Such results have suggested that microorganisms may be the true producers of most marine metabolites.

\subsection{Biological Activity of Aburatubolactams}

Superoxide anions are thought to be closely associated with inflammation, cancer, and aging. ${ }^{36}$ Superoxide anion generation was assayed using a modification of cytochrome $\mathrm{C}$ reduction methods. Aburatubolactams (20, 21, 22) inhibited TPA-induced superoxide anion generation by human neutrophils ( $\mathrm{IC}_{50} 26,6.3,2.7 \mu \mathrm{g} / \mathrm{ml}$, respectively). The mechanism of action and the in vivo behavior of aburatubolactams are currently under investigation.

\section{Conclusion}

As described above, bioactive alkaloids were isolated from marine organisms in the present study. These structures were clarified by spectroscopic analysis and synthetic methods. The biogenesis of these compounds was proposed based on comparisons with their analogs. Additional biological activities of these compounds in vivo are currently under investigation in our laboratories.

Thanks to the development of new analytical instruments and techniques, numerous compounds have been isolated and elucidated from natural resources during the past 30 years. Continued study of natural resources is a promising field for the discovery of novel bioactive compounds.

Acknowledgements We would like to thank Dr. K. Yamada (Nagoya University) and Dr. K. Yamaguchi (Tokyo University of Fisheries) for the biological activity test. This study was supported in part by Grants-in-Aid for Scientific Research from the Ministry of Education, Culture, Sports, Science and Technology, Japan. We are indebted to Wako Pure Chemical Industries, Ltd.; Banyu Pharmaceutical Co., Ltd.; and the Naito Foundation for their financial support.

\section{References}

1) Rosewater, J. Indo-Pacific Mollusca, 1961, I, 53/501/632.

2) (a) Otofuji, T.; Ogo, A.; Koishi, J.; Matsuo, K.; Tokiwa, H.; Yasumoto, T.; Nishihara, K.; Yamamoto, E.; Saisho, M.; Kurihara, Y.; Hayashida, K. Food Sanit. Res. 1981, 31, 76; (b) Department of Public Health, Fukuoka Prefecture, Food Sanit. Res. 1976, 26, 11.

3) Zheng, S. Z.; Huang, F. L.; Chen, S. C.; Tan, X. F.; Zuo, J. B.; Peng, J.; Xie, R. W. Zhongguo Haiyang Yaowu (Chinese J. of Marine Drugs). 1990, 33, 33.

4) (a) Uemura, D.; Chou, T.; Haino, T.; Nagatsu, A.; Fukuzawa, S.; Zheng, S. Z.; Chen, H. J. Am. Chem. Soc. 1995, 117, 1155; (b) Chou, T.; Kamo, O.; Uemura, D. Tetrahedron Lett., 1996, 37, 7023; (c) Chou, T.; Haino, T.; Kuramoto, M.; Uemura, D. Tetrahedron Lett., 1996, 37, 4027; (d) Takada, N.; Uemura, N.; Suenaga, K.; Chou, T.; Nagatsu, A.; Haino, T.; Yamada, K.; Uemura, D. Tetrahedron Lett., 2001, 42, 3491
5) (a) Satake, M.; Murata, M.; Yasumoto, T.; Fujita, T.; Naoki, H. J. Am. Chem. Soc. 1991, 113, 9859; (b) Naoki, H.; Murata, M.; Yasumoto, T. Rapid Commun. Mass Spectrum. 1993, 7, 179.

6) Takada, N.; Uemura, N.; Suenaga, K.; Uemura, D. Tetrahedron Lett. 2001, 42, 3497.

7) Kock, A. E.; Halloran, M. M.; Haskell, C. J.; Sah, M. R.; Polverini, P. J. Nature, 1995, 376, 517 and references cited therein.

8) Osborn, L.; Hession, C.; Tizard, R.; Vassallo, C.; Huhovoskyi, S.; Chi-Rosso, G.; Hobb, R. Cell, 1988, 59, 1203.

9) Kuramoto, M.; Chou, T.; Yamada, K.; Chiba, T.; Uemura, D. Tetrahedron Lett. Tetrahedron Lett. 1996, 37, 4023.

10) (a) Nikon, A. J. Am. Chem. Soc., 1957, 79, 243; (b) Bohlmann, F. Chem. Ber., 1958, 91, 2157.

11) Arimoto, H.; Hayakawa, I.; Kuramoto, M.; Uemura, D. Tetrahedron Lett. 1998, 39, 861.

12) (a) Trauner, D.; Schwarz, J. B.; Danishefsky, S. J. Angew. Chem., Int. Ed. 1999, 38 3542; (b) Trauner, D.; Danishefsky, S. J. Tetrahedron Lett. 1999, 40, 6513.

13) Boschelli, D. H.; Karmer, J. B.; Khatana, S. S.; Sorenson, R. J.; Connor, D. T.; Ferin, M. A.; Wright, C. D.; Lesch, M. E.; Imre, K.; Okonkwo, G. C.; SchrieD. J.; Conroy, M. C.; Ferguson, E.; Woelle, J.; Saxena, U. J. Med. Chem., 1995, 38, 4597.

14) (a) Dennis, E. A. In: The Enzymes. Boyer, P. D. (ed.), Academic Press, New York 1983, 307; (b) van den Bosch, H. Biochim. Biophys. Acta, 1980, 604, 191; (c) Arita, H.; Nakano, T.; Hanasaki, K. Prog. Lipid Res., 1989, 28, 273.

15) Scheuer, P. J.; de Silva, E. D. Tetrahedron Lett. 1980, 21, 1611.

16) Albizati, K. F.; Holman, T.; Faulkner, D. J.; Glaser, K. B.; Jacobs, R. S. Experientia 1987, 43, 949.

17) (a) Potts, B. C. M.; Faulkner, D. J.; de Carvalho, M. S.; Jacobs, R. S. J. Am. Chem. Soc. 1992, 114, 5093; (b) Potts, B. C. M.; Faulkner, D. J.; Jacobs, R. S. J. Nat. Prod. 1992, 55, 1701.

18) Kramer, R. M. et al. Exp. Med. Biol. 1990, 275, 35.

19) Kim, D. K.; Kudo, I.; Fujimori, Y.; Mizushima, H.; Masuda, M.; Kikuchi, R.; Ikizawa, K; Inoue, K. J. Biochem., 1990, 108, 903.

20) Chou, T.; Haino, T.; Kuramoto, M.; Uemura, D. Tetrahedron Lett. 1996, 37, 4027.

21) (a) Carson, M. W.; Kim, G.; Hentemann, M. F.; Trauner D.; Danishefsky, S. J. Angew. Chem., Int. Ed. 2001, 40, 4450.; (b) Carson, M. W.; Kim, G.; Danishefsky, S. J. Angew. Chem., Int. Ed. 2001, 40, 4453.

22) Hayakawa, I.; Arimoto, H.; Uemura, D. Heterocycles, 2003, 59, 441.

23) Ducy, P.; Desbois, C.; Boyce, B.; Pinero, G.; Story, B.; Dunstan, C.; Smith, E.; Bonadio, J.; Goldstein, S.; Gundberg. C; Bradlley, A.; Karsenty, G. Nature, 1996, 382, 448

24) Fukuzawa, S.; Hayashi, Y.; Uemura, D.; Nagastu, A.; Yamada, K.; Ijyuin, Y. Hetcrocycl. Commun., 1995, 1, 207.

25) (a) Rao, C.B.; Anjaneyula, A.S.R.; Sarma, N.S.; Venkatateswarlu, Y.; Rosser, R.M.; Faulkner, D.J.; Chen, M.H.M.; Clardy, J. J. Am. Chem. Soc. 1984, 106, 7983; (b) Rao, C.B.; Anjaneyula, A.S.R.; Sarma, N.S.; Venkatateswarlu, Y.; Rosser, R.M.; Faulkner, D.J.; Chen, M.H.M.; Clardy, J. J. Org. Chem. 1985, 50, 3757; (c) Atta-ur-Rahman; Alvi, K.A.; Abbas, S.A.; Choudhary, M.I.; Clardy, J, Tetrahedron Lett. 1989, 30, 6825 .

26) (a) Kuramoto, M.; Hayashi, K., Fujitani, Y.; Yamaguchi, K.; Tsuji, T.; Yamada, K.; Ijyuin, Y.; Uemura, D. Tetrahedron Lett., 1997, 38, 5683; (b) Kuramoto, M.; Hayashi, K.; Yamaguchi, K.; Yada, M.; Tsuji, T.; Uemura, D. Bull. Chem. Soc. Jpn., 1998, 71, 771; (c) Kuramoto, M.; Yamaguchi, K.; Tsuji, T.; Uemura, D. In: Drugs from the Sea, Fusetani, N. (ed.), KARGER, Basel, 2000, 98.

27) Turner, C. H.; D. B. Burr, Bone, 1993, 14, 595.

28) Yamaguchi, K.; Hayama, T.; Makita, T.; Tsuji, T. J. Bone Miner. Metab. 1997, 15, 138.

29) Kuiper, G.G.J.M.; Enmark, E.; Pelto-Huikko, M.; Nilsson, S.; Gustafsson, J. Proc. Natl. Acad. Sci. USA, 1996, 93, 5925.

30) Nakamura, H.; Kawase, Y.; Maruyama, K.; Murai, A. Bull. Chem. Soc. Jpn. 1998, 71, 781.

31) Krochak, H. M.; Vienne, K.; Rutherford, L. E.; Wilkenfeld, C.; Finkelstein, M. C.; Weissmann, G., J. Biol. Chem. 1984, 259, 4076.

32) Bae, M.-A.; Yamada, K.; Ijyuin, Y.; Tsuji, T.; Yazawa, K.; Tomono, Y.; Uemura, D. Heterocycl. Commun., 1995, 2, 315.

33) Ito, S.; Hirata, Y. Bull. Chem. Soc. Jpn., 1977, 50, 1813. 
34) Shigemori, H.; Bae, M.-A.; Yazawa, K.; Sasaki, T.; Kobayashi, J. J. Org. Chem., 1992, 57, 4317.

35) Kanazawa, S.; Fusetani, N.; Matsunaga, S. Tetrahedron Lett., 1993, 34, 1065.

36) (a) Nakano, Y.; Kawaguchi, T.; Sumimoto, J.; Takizawa, T.; Uetsuki, S.; Suenaga, M.; Kido, M. J, Antibiot. 1991, 44, 52; (b) Badwey, J. A.; Karnovsky, M. L. Annu. Rev. Biochem. 1980, 49, 695.

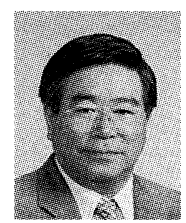

Daisuke Uemura is Professor of Nagoya University. He was born in Gifu in 1945, and received his $\mathrm{Ph} . \mathrm{D}$. in 1975 from Nagoya University. He joined the faculty of Nagoya University as an Assistant Professor in 1973. He was on the chemistry faculty at Shizuoka University from 1979-1997. In 1997, he moved to Nagoya University, where he is currently Professor of Chemistry. He was the 1977 recipient of the Award for Young Chemists, awarded by the Chemical Society of Japan. His current interests are in the area of isolating complex natural products. He is the head investigator of a Scientific Research in Priority Area (A) study entitled "Targeted Pursuit of Challenging Bioactive Molecules" (The Ministry of Education, Science, Sports and Culture).

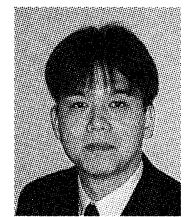

Hirokazu Arimoto is an Associate Professor of Nagoya University. He was born in Yokohama in 1966. He received his Ph.D. in 1995 from Keio University. After spending 7 years (Assistant Professor 1994-1999, Associate Professor 1999. 2002) at Shizuoka University, he moved to Nagoya University as an Associate Professor of Chemistry in 2001. He is also a researcher at the Institute for Advanced Research at Nagoya University (2003-2005), and in the Precursory Research for Embryonic Science and Technology Program of the JST (20012004). He was a recipient of the 2001 Incentive Award in Synthetic Organic Chemistry, Japan. His current research interests are in the total synthesis of natural products and polyvalent biologically active polymers.

Makoto Kuramoto is an Assistant Professor of Ehime University. He was born in Kawasaki in 1969. He received his Ph.D. in 1998 from Shizuoka University. $\mathrm{He}$ joined Ehime University, as an Assistant Professor in 1997. (Advanced Instrumentation Center for Chemical Analysis, 1997-2002, Integrated Center for Science, 2003- ). He was a recipient of the 2003 Award for Young Chemists from the Japanese Association for the Pursuit of New Bioactive Resources. His work focuses on the search for bioactive compounds from marine organisms. 